\title{
The Determination of Nitrate in the Sea by Means of Reduced Strychnine.
}

By

\author{
L. H. N. Cooper, Ph.D., A.I.C., \\ Assistant Chemist at the Plymouth Laboratory.
}

With 1 Figure in the Text.

Thompson and Johnson ( $(\mathbf{y})$ have criticised the method of analysis for nitrate in sea-water by means of reduced strychnine $(2,3,4)$. They state : "Plans had been made to use Harvey's (1928)* method for the nitrate ions but considerable difficulty was encountered in preparing the reagent. Furthermore, any oxidising material present in the water would rapidly react with the reagent. Thus iodate ions appeared to give a reaction similar to the nitrate ions. Other investigators on the Pacific Coast have experienced considerable difficulty with this particular nitrate reaction and in general it has been discarded as being unreliable from a quantitative standpoint."

In view of the precautions necessary, it seems desirable to stress that the method has given a good general picture of seasonal changes in nitrate in the sea, that the reagent presents no undue difficulty of preparation and that it has been used with success by a number of independent workers in Europe.

Following in detail the method of preparation described in (4), little difficulty has been experienced by the writer in obtaining good batches of reagent from the majority of the strychnine reductions. It was sometimes necessary to continue the reduction for 36 hours (3 days of 12 hours each) to obtain a product of suitable strength. The two most probable sources of contamination are an impure atmosphere such as that of a large industrial town, and impure reagents, particularly sulphuric acid containing nitric acid. Wattenberg (private communication through Mr. Harvey) avoids any risk of atmospheric contamination by passing a current of an inert gas through the stoppered reduction flask. This variation has not been tried at Plymouth.

Impure sulphuric acid is the commonest source of trouble. A few preliminary experiments have been made to devise a method for removing

\footnotetext{
* Reference $\mathbf{5}$ in appended bibliography.
} 
nitric acid from sulphuric acid. Most of the impurity in a grossly contaminated acid may be removed by heating for one or two hours at $300^{\circ} \mathrm{C}$. with a few crystals of ammonium sulphate. The method, which is dependent on the breakdown of ammonium nitrate at a high temperature to nitrous oxide and water, has not yet been conclusively shown to remove the last trace of nitric acid. It may be worth following up by anyone

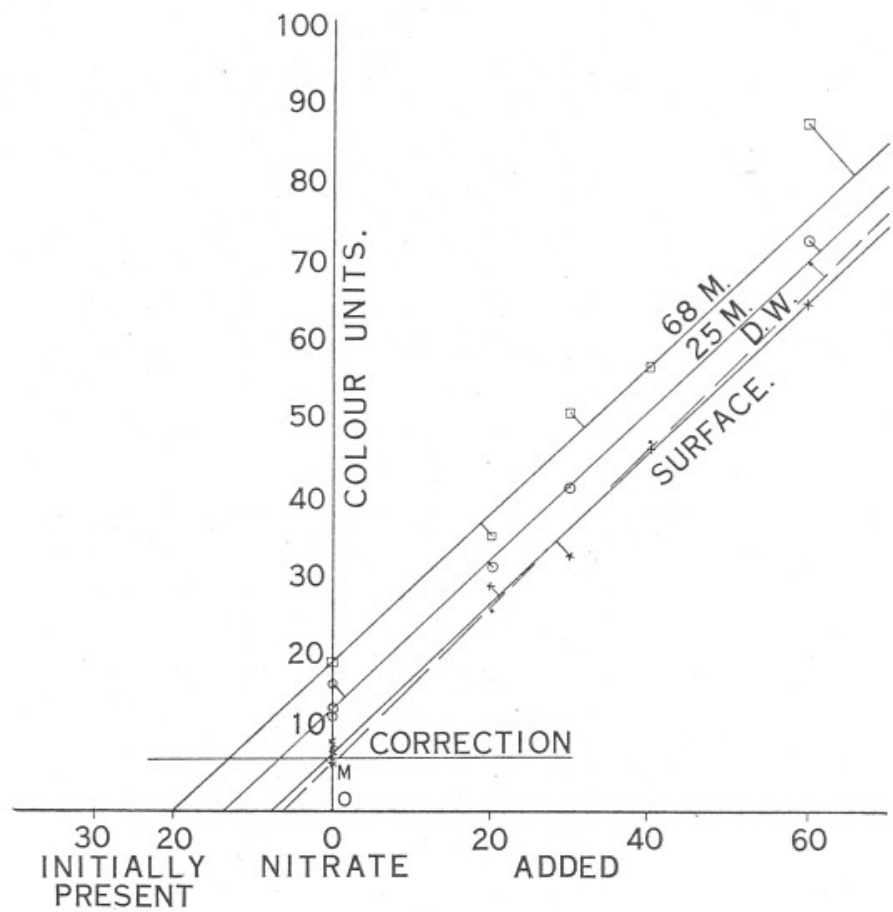

FIG. 1.-Graphical Method of Evaluating Nitrate from Colour Measurements.

Samples collected and preserved at E1, July 10, 1931, analysed July 20-21 with reagent six weeks old. Curves for water from surface, $25 \mathrm{~m}$. and $68 \mathrm{~m}$. (bottom) and for distilled water redistilled from baryta (D.W.) as marked. The horizontal line shows the blank correction for colour given by distilled water alone.

unable to obtain commercially a nitrogen-free sulphuric acid. The colour given with distilled water by a satisfactory reagent did not exceed that given by 5-8 mg. of nitrate-nitrogen per cubic metre.*

In order to carry out the determination of nitrate, 6 c.c. of the reagent were added to 5 c.c. portions of sea-water or of distilled water to some of

* Atkins (Nature, 1932, 129, p. 98) has recently achieved the same object by cautiously adding hydrogen sulphide or ammonium sulphide in such quantity that a trace of nitric acid remains, sufficient to give the faintest perceptible colour with a diphenyl-benzidine reagent. 
which $10,20,30,40$, or $60 \mathrm{mg}$. per cubic metre of nitrate-nitrogen had been added. The resultant colour in each case was compared 18 hours later in a Duboscq colorimeter with a standard solution of safranine. This dyestuff matches solutions containing up to $50 \mathrm{mg} . / \mathrm{m}^{3}$ of nitratenitrogen exactly and the difference in shade for higher concentrations is scarcely significant. Its solutions at the required dilution obey Beer's Law. A $0 \cdot 0008 \%$ solution of safranine (from Grübler, dyeing strength not stated) has been arbitrarily taken as containing 100 colour units, and with a good batch of nitrate reagent is equivalent to from 90 to $130 \mathrm{mg}$. of nitrate-nitrogen per cubic metre. When examining solutions weaker than this the safranine solution has been proportionally diluted. This is a simple quantitative method of evaluating the sensitivity of a batch of reagent and would enable a comparison to be made between the products of different laboratories. The safranine does not fade appreciably in the colorimeter during several hours' continuous working with a "daylight" lamp and its tint is not altered by traces of hydrochloric acid fumes.

When the colour given by various samples had been found in terms of the standard colour unit, the actual nitrate content was evaluated by a graphical method (Fig. 1). Since the colour developed by a reagent less than six weeks old with distilled water is less than that with sea-water the blank correction in such a case may be too small.

In the Figure the results for distilled water redistilled from baryta and E1 surface water are nearly co-linear, showing that the surface water was completely exhausted of nitrate. The length OM represents colour due to reagent alone. The 25-metre and 68-metre E1 samples with added nitrate gave greater depths of colour which gave linear curves on the graph parallel with the first two. In these cases a certain amount of nitrate was initially present in the water.

The method of calculation is shown by the following fictitious example :

Suppose that the reagent gives 7 colour units with distilled water and 54 units with an unknown sample, and that the graph shows that 100 colour units are given by sea-water containing $90 \mathrm{mg}$. of nitrogen per cubic metre present as nitrate + nitrite without allowing for the blank correction.

Since 100 colour units $=90 \mathrm{mg} \cdot / \mathrm{m} \cdot{ }^{3} \mathrm{~N}$.

$$
\begin{aligned}
& \text { Then } 54,, \quad, \quad=\frac{54 \times 90}{100}=48.6 \mathrm{mg} \cdot / \mathrm{m} \cdot{ }^{3} \mathrm{~N} \ldots \ldots \ldots \ldots \ldots \\
& \text { And } 7 \quad, \quad, \quad=\frac{7 \times 90}{100}=6.3 \mathrm{mg} \cdot / \mathrm{m} \cdot{ }^{3} \mathrm{~N} \ldots \ldots \ldots \ldots \ldots
\end{aligned}
$$

Subtracting the blank correction (2) from (1), the true amount of nitrate $\left(+\right.$ nitrite) present is $48 \cdot 6-6 \cdot 3=42 \cdot 3 \mathrm{mg} . / \mathrm{m} .^{3} \mathrm{~N}$.

This method of evaluating the results is in practice very simple. 


\section{Interference by Organic Material.}

Presence of organic material, particularly phytoplankton during the spring or autumn outbursts, may completely invalidate the method unless first removed (4). Samples preserved with mercuric chloride brought in from the International Station, E1, on March 23, 1931, gave an absurd set of results. Centrifuging the samples in an electric centrifuge for fifteen minutes was found to remove the source of trouble, so that when various known amounts of nitrate were added to three of the samples the usual linear relation between colour and nitrate concentration was obtained.

When much plankton is present in the water, it would seem essential to centrifuge the samples or to remove living and dead organic matter in some other way before making the determination. This is of much importance since nitrate figures are of most interest when the plankton outbreak is occurring.

Thus, during twelve months' work the method, given due care, has been found well able to give concordant results, such as those shown in Figure 1. An occasional high value, due apparently to contamination, had to be discarded.

\section{INFLUENCE OF IODATE.}

The depth of colour developed by different amounts of iodate, calculated as $\mathrm{mg}$. iodine per cubic metre, is shown in Table I as if it were due to nitrate expressed as mg. nitrogen per cubic metre. It will be seen that the ratios

\section{TABLE I.}

\section{Colour Development Due to Iodate.}

\section{Iodate expressed as iodine $\mathrm{mg} \cdot / \mathrm{m} .^{3}$}

$$
\begin{array}{r}
42,400 \\
21,200 \\
4,240 \\
4,240 \\
2,120 \\
2,120 \\
1,060 \\
1,060
\end{array}
$$

Increase in colour due to iodate expressed in terms of nitrate-nitrogen mg./m. ${ }^{3}$

$$
\begin{array}{r}
71 \cdot 4 \\
28 \cdot 6 \\
3 \cdot 4 \\
2 \cdot 9 \\
1 \cdot 5 \\
1 \cdot 5 \\
1 \cdot 2 \\
3 \cdot 0
\end{array}
$$

are very large and that the colour due to $4,000 \mathrm{mg}$. of iodine per cubic metre gives a depth of colour little greater than the experimental error inherent in the method. Such a relatively enormous amount of iodine 
is known not normally to be present in sea-water (6) and therefore the possibility that iodate interferes may be dismissed.

Iron has already been investigated (2) and found to be without appreciable effect in the concentrations in which it is present in the sea except possibly in inshore waters. The zero values found in summer also support the contention that other oxidising agents are not likely to interfere.

\section{Effect of Nitrite.}

The reagent is recognised as determining both nitrate and nitrite, but it had not been finally shown whether equivalent amounts of each give rise to the same intensity of colour. If the relation is definitely known and the nitrite has been determined with the Griess-Ilosvay reagent, the true. amount of nitrate present may be found by difference. It seems that solutions containing added nitrite give more erratic results than those containing added nitrate. Two possible reasons may be adduced for this. The free nitrous acid produced in presence of sulphuric acid is certainly more unstable than nitric acid and may tend spontaneously to decompose. Furthermore, nitrous acid may be more liable to react with organic matter.

One set of determinations made on water, collected on September 25, 1931, at E1, 5 metres depth, which was not centrifuged gave an excellent linear relation which showed nitrite exactly equivalent to nitrate. In four other sets on samples collected on July 10, September 8 and November 30, 1931, from E1 surface or 25 metres, less satisfactory curves were obtained since the experimental points did not show good alignment and the ratio colour due to nitrite

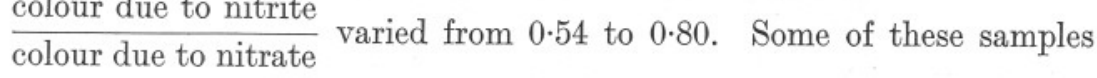
were centrifuged (including that which gave the figure 0.54 ), some not. Ideally, therefore, the ratio approaches unity, but under standard working conditions it appears often to be about $0 \cdot 7$ or $0 \cdot 8$.

As a corollary, when nitrite is very high in the sea (Atkins, 1, found up to $38.9 \mathrm{mg}$. of nitrite-nitrogen per cubic metre at E1 on August 29, 1928) difficulty may be anticipated in getting concordant results with the reagent.

Acknowledgements are due to Mr. H. W. Harvey of this Laboratory for valuable criticism and advice, and to Dr. E. J. Allen for his general interest.

\section{SUMMARY.}

The recent criticism of Thompson and Johnson ( $(\boldsymbol{y})$ of the method of determining nitrate in the sea by means of reduced strychnine is held to be unsound. 
Preparation of the reagent given due care and pure materials has offered little difficulty.

A possible method for the preparation of nitrate-free sulphuric acid is outlined.

The effect of iodate in concentrations likely to be met in the sea is negligible.

Interference by organic material has been avoided by first centrifuging all samples obtained during periods of plankton activity.

The relative intensity of colour given by nitrate and by nitrite nitrogen is discussed.

\section{REFERENCES.}

1. Aткins, W. R. G. 1929. Seasonal Changes in the Nitrite Content of Sea-Water. Journ. Mar. Biol. Assoc., N.S., Vol. XVI, pp. 515-518.

2. Harvey, H. W. 1926. Nitrate in the Sea. Journ. Mar. Biol. Assoc., N.S., Vol. XIV, pp. 71-88.

3. - 1928. Nitrate in the Sea. II. Journ. Mar. Biol. Assoc., N.S., Vol. XV, pp. 183-190.

4. _ 1928. Concerning Methods for Estimating Phosphates and Nitrates in Solution in Sea-Water. Section II. Estimation of Nitrates and Nitrites. Conseil Int. p. l'Exploration de la Mer. Rapports et Procès-verbaux, Vol. 53, p. 96.

5. — 1928. Biological Chemistry and Physics of Sea-Water. Cambridge University Press.

6. Reith, J. F. 1930. Der Jodgehalt von Meerwasser. Rec. trav. chim. des Pays-Bas, Vol. 49, p. 142.

7. Thompson, T. G., and Johnson, M. W. 1930. The Sea-Water at the Puget Sound Biological Station from September, 1928, to September, 1929. Publ. Puget Sound Biol. Station, Vol. 7, pp. 345368. 